\title{
Beitrag zu der Lehre über den Einfluss der Erregung nicht identischer Netzhautpunkte auf die Stellung der Sehachsen.
}

\author{
Von \\ Dr. Alfred Graefe.
}

\begin{abstract}
Nachfolgenden Fall halte ich der Mittheilung nicht für unwerth, weil er einen eben so interessanten als belehrenden Beitrag zu dem Kapitel der Diplopia biocularis und dem Einflusse derselben auf die Stellung der Augenachsen liefert.

Herr H . . in Halle, c. 45 Jahr alt, leidet auf dem rechten Auge schon von Kindheit auf, an einer eigenthümlichen Art von Sehschwäche. Die genaucre AnaJyse derselben ergicbt, dass ein centrales Scotom vorhanden ist, dessen horizontale Ausdehnung durch einen Winkel von c. $20^{\circ}$ bestimmt wird, während die vertikale nur etwas mehr als die Hälfte davon beträgt. Ophthalmoskopisch nachweisbar ist eine die Gegend der Macula lutea und ihre nächste Nachbarschaft occupirende umschriebene Chorioidealerkrankung, in deren Folge auch die centralen Theile der Netzhaut einer pathologischen Veränderung entgegen gingen. Das excentrische Sehen dieses Auges ist ein fast normales,
\end{abstract}


während innerhalb des mit scharfen Grenzen zu umschreibenden centralen Gesichtsfeldsdefektes nicht einmal eine hell brennende Kerzenflamme in dunklem Zimmer erkannt werden kann. Beide Augen sind hyperpresbyopisch gebaut.

Das rechte Augo steht in sehr leichtem Grade divergent, jedoch nur so wenig, dass die objective Schätzung darüber in Ungewissheit lassen könnte. Da zur Bestätigung der Abweichung die gewöhnlichen monocularen Fixationsversuche hier, bei dem Vorhandensoin eines centralen Scotoms, natürlich wegfallen mussten, bediente ich mich zur Constatirung derselben der Prismen. Wurden solche in genau vertikaler Richtung mit der Basis bald nach oben, bald nach unten vor das rechte Auge gebracht, so gab der Kranke Doppelbilder an, welche einmal, conform der prismatischen Ablenkung, über einander lagen, daneben jedoch in Uebereinstimmung mit der vermutheten Divergenz eine leichte Kreuzung zeigten. Dass der Kranke für gewöhnlich nicht doppelt sah, versteht sich von selbst, da die mit dem Centrum der linken Netzhaut gleichzeitig eingestellte Parthie der rechten noch durchaus in Bereiche der centralen pathologischen Veränderung lag. Die Behauptung des Patienten, dass or selhst bei der Arbeit in der Nähe, wie beim Lesen, Schreiben etc., mit beiden Augen besser sähe, als mit dem linken allein, veranlassten mich zu einer genaueren Prüfung des gemeinschaftlichen Sehaktes überhaupt und stelle sich hierbei Folgondes heraus:

Wurde vor das gesunde linke Auge, während dasselbe eine in der Mittellinie c. $2^{\prime}$ vor der Angesichtsfläche befindliche Kerzenflamme fixirte ein 20 grädiges Prisma mit der Basis nach aussen angelegt, so trat mit der Ablenkung dieses Auges nach innen zunächst eine associirte Mitbowegung des rechten nach aussen hin Archiv fiir Ophthalmologie. V. 1. 
ein, sofort aber kehrte dieses Auge in seine vorige Stellung zurück, so dass, trotz der (auf das linke Auge beschränkten) Einseitigkeit des centralen Sehens ein convergirendes Schielen entstand, ganz wie bei einem ungestörten doppelseitigen Sehakte der Fall ist. In Anbetracht dieser eigenthümlichen Erscheinung erwähne ich nochmals ausdrücklich, dass, wenn man untes denselben Verhältnissen, statt das linke Auge mit einem Prisma zu versehen, dasselbe verdeckte, das Fixationsobjekt von dem rechten Auge, welches dabei genau in seiner Stellung verharrte, durchaus nicht wahrgenommen wurde. Ich konnte mir den Vorgang nur so deuten, dass in demselben Augenblicke, in welchem das Prisma vor das linke Auge gebracht und damit das rechte zu einer Bewegung nach aussen angeregt wurde, ein excentrisch nach aussen liegender Punkt der rechten Netzhaut von dem Bilde der Kerzenflamme getroffen wurde, welcher bercits ausser dem Bereiche der pathologischen Veründerung lag, dessen Erregung somit zur Diplopie führte, und dass das rechte Auge, bestimmt durch die sofort entstehende Gene der Diplopie, zur Erhaltung des Einfachsehens wieder die unempfindliche centrale Netzhautregion einstellen, also wieder nach innen hin abweichen musste. Nun aber war es nicht möglich, die Doppelbilder in dem Momente, als das Prisma vor das Auge gelegt wurde, dem Kranken zur Perception zu bringen, auch wenn man zur Differenzirung der Bilder verschieden gefärbte Gläser wählte und den übrigens sehr intelligenten und in naturwissenschaftlicher Beobachtung selbst geübten Kranken auf jede erdenkliche Art auf das zu erwartende Phaenomen aufmerksam machte.

Zur weiteren Prüfung der Richtigkeit meiner Auffassung legte ich nun dasselbe 20 grädige Prisma mit der Basis nach aussen vor das kranke rechte Auge. 
Auf diese Weise musste, ceteris paribus, das Bild der (vom linken Auge) fixirten Lichtllamne im rechten Auge auf demselben excentrisch nach aussen liegenden Netzhautpunkt fallen, welcher bei der ersten Ausführung des Experiments vorübergehend dadurch eingestellt worden war', dass dieses Auge im Momente der Interposition das Prisma vor das linke, zu ciner associirten Bewegung nach aussen angeregt worden war. Stimmte die Probe, so musste das rechte Auge jetzt unter dem Prisma nach innen hin abweichen. Und in der That war dies constant der Fall: während das linke Auge unverändert in seiner fixirenden Richtung verharrte, schielte das rechte jetzt nach innen.

Der Sehakt genoss also in diesem eigenthümlichen Fall noch immer eines gewissen regulatorischen Impulses des rechten Netzhautcentrums, obgleich dasselbe für Licht vollständig unempfindlich war. Während unter normalen Verhältnissen das Einfachsehen eines fixirten Objektes durch Combination der identischen Netzhautpunkte realisirt wird, so geschicht dies hier durch Combination einer empfindlichen Netzhautstelle mit einer nicht empfindlichen, wie dort der gedachte regulatorische Impuls - in gewissen Grenzen wenigstens - etwas so zwingendes hat, dass unter seinem Einflusse ein künstliches Schiclen entsteht, so ist es thatsächlich auch hier der Fall.

Auch bei der zweiten Ausführung des Experiments konnten Doppelbilder in dem Momente, als das Prisma vorgelegt wurde, auf keine Weise wahrgenommen werden. Dass die durch das angewandte Prisma nach aussen hin abgelenkten Lichtstrahlen aber wirklich einen bereits empfindlichen Punkt der rechten Netzhaut trafen, konnte, wenn es nach dem bereits Angefïhrten überlaupt noch eines anderen Beweises bedurlte, jetzt ganz direkt nachgewiesen werden. Bedeckte man nämlich - 
immer unter den Anfangs bestimmten Bedingungen das gesunde linke Auge mit der Hand, so sah das rechte, wie schon gesagt, nichts von dem Fixationsobjeckte. Verharrte das rechte Auge nun genau in derselben Richtung (eine Aufgabe, welche der Kranke ganz vorzüglich löste), während man das besagte Prisma mit der Basis nach aussen vor dasselbe legte, so gab der Patient augenblicklich die Wahrnehmung der Flamme an. Wäre es erlaubt, aus diesem Factum, dessen Realität durchaus keinen $Z$ weifel übrig lässt, einen physiologischen Schluss zu ziehen, so müssten wir diesen in folgender Weise formuliren: Dic Erregung zweier nicht identischen Netzhautpunkte kann auch dann als motorischer Impuls in der Regulirung des Sehaktes auftreten, wenn die Doppelbilder sensoriell gar nicht percipirt werden. 